\title{
Operational Evaluation of Air Traffic Flow Management in the Philippines*
}

\author{
By Masahiko ISHIDA \\ NEC Corporation, Tokyo, Japan
}

(Received December 26th, 2013)

\begin{abstract}
In the past decade, both the economy and air traffic demand have been growing rapidly in the Philippines. As a result, Ninoy Aquino International Airport (NAIA) has had to cope with increasingly heavy traffic. To mitigate the effects of this traffic, an air traffic flow management (ATFM) system was introduced in the Philippines. In this paper, background on introducing the ATFM system is presented and its successful results in reducing the holding time of flights waiting to land at the NAIA are reported on.
\end{abstract}

Key Words: Air Traffic Flow Management, Ground Delay Program, Air Traffic Management

\section{Nomenclature}

$N \quad$ : the number of aircraft waiting to land in a unit of time

A : the number of aircraft estimated to arrive in a unit of time

$L \quad$ : the number of aircraft that landed in a unit of time

$H \quad$ : estimated holding time

$n \quad$ : working value for $\mathrm{N}$

$T \quad$ : time

$t \quad$ : time variable

Subscripts

i : current

0 : initial

\section{Introduction}

In the past decade, both the economy and air traffic demand have been growing rapidly in the Philippines. Therefore, Ninoy Aquino International Airport (NAIA) has had to cope with increasingly heavy traffic. To mitigate the effects of this traffic, an air traffic flow management (ATFM) system was introduced in the Philippines.

\section{Background}

The Philippines is an archipelago comprising over 7,000 islands, including the main ones: Luzon Island and Mindanao Island. Figure 1 is a map of the country. To its north across the Luzon Strait lies Taiwan. West across the South China Sea is Vietnam. The Sulu Sea to the southwest lies between the country and the island of Borneo.

(C) 2014 The Japan Society for Aeronautical and Space Sciences.

*Presented at the 2013 Asia-Pacific International Symposium on Aerospace

Technology (APISAT-2013), Nov. 20-22, 2013, Takamatsu, Japan
To the south, the Celebes Sea separates it from other Indonesian islands. It is bounded on the east by the Philippine Sea.

The Philippines' gross domestic product (GDP) increased 7.6\% in 2010 year-on-year. Its GDP growth rate is reported by its National Statistical Coordination Board, as detailed in Table 1. The rate in 2011 slowed to $3.9 \%$ due to the effects of the global recession in numerous countries. However, in 2012, the economy recovered, expanding $6.4 \%$ in the first quarter of 2012 quarter-on-quarter.

Table 1. Economic growth in the Philippines. ${ }^{1)}$

\begin{tabular}{|c|c|c|c|}
\hline & FY2009 & FY2010 & FY2011 \\
\hline $\begin{array}{c}\text { Nominal GDP } \\
\text { (US\$100 M) }\end{array}$ & 1,683 & 1,996 & 2,248 \\
\hline GDP growth rate & $1.1 \%$ & $7.6 \%$ & $3.9 \%$ \\
\hline
\end{tabular}

As an archipelago, air transportation is essential for inter-island travel and international trips. Therefore, the Philippines has 86 airports around the country, and 10 are international ones. NAIA (International Civil Aviation Organization code: RPLL) is the main international airport. Clark Airport (RPLC) and Subic Bay Airport (RPLB) are also major airports and are well-known as former US airbases.

Other international airports are Laoag Airport (RPLI) on Luzon Island in the north of the country and Davao Airport (RPMD), Tambler Airport (RPMR) and Zamboanga Airport (RPMZ) on Mindanao Island in the south. In addition, the central Philippines has Kalibo Airport (RPVK), Puerto Princesa Airport (RPVP) and Cebu Airport (RPVM) on the Visayas Islands. 


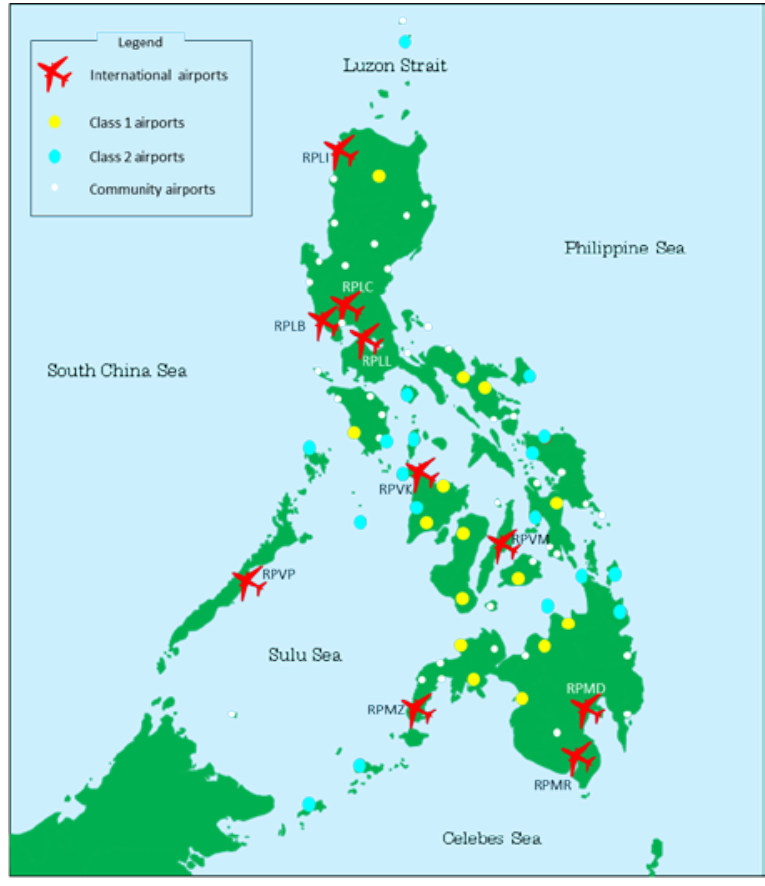

Fig. 1. Airports in the Philippines.

The other airports in the country are categorized into 15 Class 1 airports, 19 Class 2 airports, and about 50 community airports.

As of 2010, NAIA's air traffic was significantly greater than in 2002 and was expected to double by 2012, as indicated by Fig. 2. To accommodate such heavy traffic, NAIA has four terminals. Terminals 1,2 and 3 are for international flights. Terminal 4 is for domestic ones.

As an international airport, NAIA has special characteristics. First, the types of aircraft range from long-haul international jets to various domestic planes, including those for general aviation (GA). A breakdown of instrument flight rule (IFR) traffic is shown in Fig. 3.

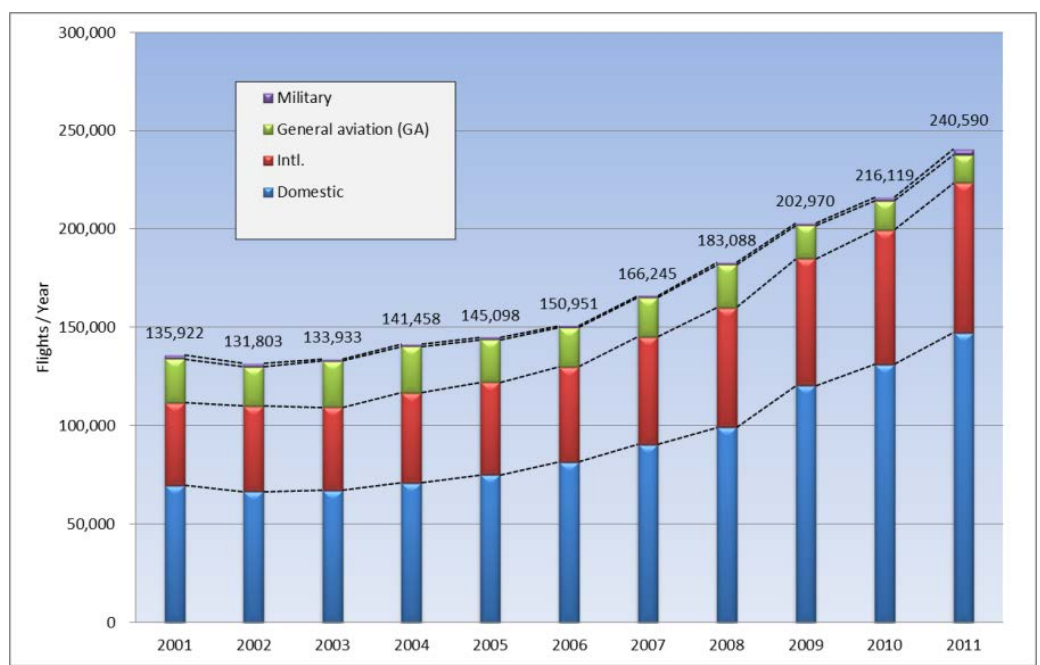

Fig. 2. Traffic growth at NAIA.

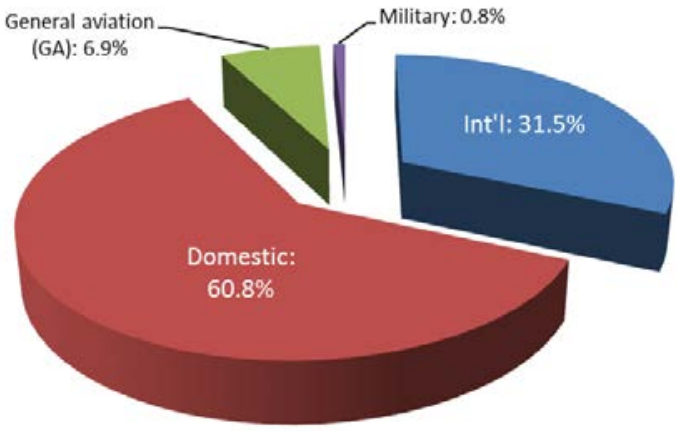

Fig. 3. NAIA's instrument flight rule (IFR) traffic for 2010.

Second, NAIA has two runways, but they intersect, and their lengths differ as shown in Fig. 4. These characteristics often make air traffic control at NAIA difficult due to varied separation minima which depend on the departure or arrival runway and types of aircraft.

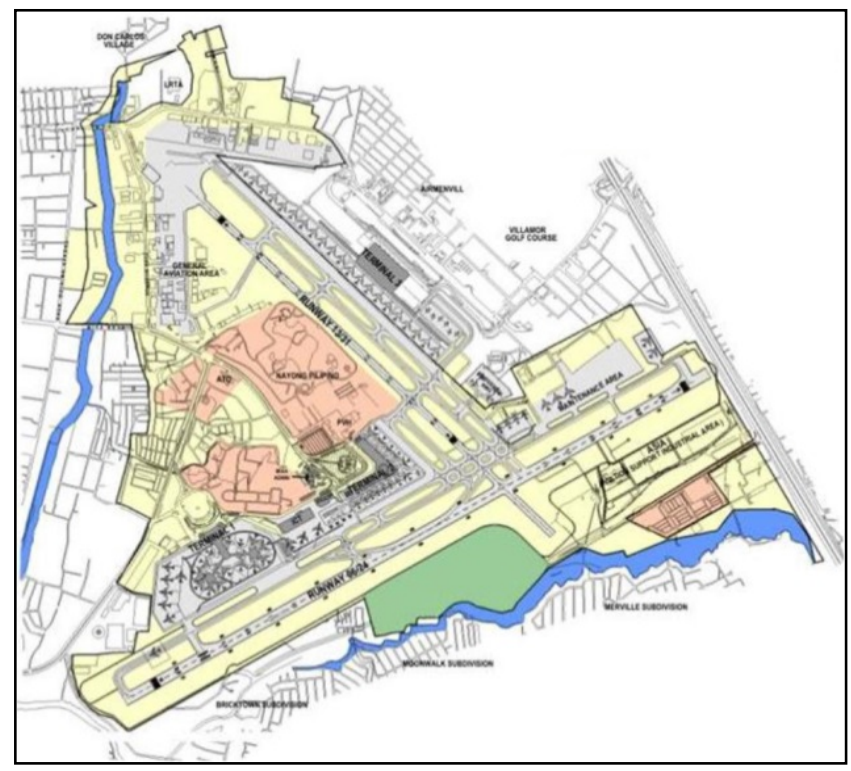

Fig. 4. Map of NAIA.

Almost every day in 2010, the airspace around the airport was filled with a lot of airplanes during the busiest period, most waiting to land at the airport. In addition, the congestion around the airport was causing a lot of problems related to the environment, economy and safety. To solve these problems, the Civil Aviation Authority of the Philippines (CAAP) decided to implement a ground delay program (GDP) to manage the air traffic flow for NAIA. GDP which is one of the concepts of ATFM, may be implemented for airports when demand exceeds capacity. 


\section{System Description and Operational Procedure}

Basically, the operation of ATFM in the Philippines is the same as the operation of ATFM at the Air Traffic Management Center (ATMC) in Fukuoka City, Japan. It is also the same as the operation of the Central Flow Management Unit of the European Organisation for the Safety of Air Navigation in Brussels, Belgium, and the Air Traffic Control Systems Command Center of the Federal Aviation Administration. Therefore, a detailed description of ATFM operation is not in this paper.

To alleviate the heavy traffic at NAIA, the GDP had to control the air traffic volume when the projected traffic demand was expected to exceed the airport's acceptable rate for a long time.

Therefore, flights to NAIA had to be issued an expected departure clearance time (EDCT) for each aircraft, as runway release time at their point of departure to mitigate constraints around the airport. Another requirement was to train the NAIA air traffic controllers and airline operators during trial operation.

\subsection{System configuration}

The system configuration for this ATFM is shown in Fig. 5. The ATFM is a Web-based client server system. The ATFM server was installed at the ATFM unit in Manila. The clients were installed at the Manila Area Control Center (ACC), Mactan sub-ACC which provides air traffic services over the southern part of the nation and is located close to Cebu Island, and Manila Tower at NAIA. They were connected via the Internet for coordination and information sharing.

\subsection{Monitoring traffic volume}

Calculating the traffic volume at NAIA requires the use of the acceptable arrival rate (AAR), which is the number of aircraft that can land at NAIA in a given unit of time.

The number of aircraft that are estimated to arrive is the summation of $A$ which is based on the flight schedule data issued in the official airline guide (OAG). The summation of $L$ gives the number of aircraft that have already landed. Thus, Eq. (1) gives the number of aircraft waiting to land at $T_{0}$.

$$
\begin{aligned}
& N\left(T_{0}\right)=\sum_{t=0}^{T_{0}} A(t)-\sum_{t=0}^{T_{0}} L(t) \\
& i=0 \\
& n=N\left(T_{i}\right)+A\left(T_{i+1}\right) \\
& i=i+1 \\
& \text { if } \mathrm{n}>A A R \text { then } N\left(T_{i}\right)=n-A A R \\
& \quad \text { else } N\left(T_{i}\right)=0 \\
& H\left(T_{i}\right)=N\left(T_{i}\right) \div A A R
\end{aligned}
$$

The calculations are done repeatedly, as indicated by Eqs. (3) - (6). This gives the number of aircraft that will be waiting to land at $\mathrm{T}$. In addition, dividing the number that already landed by the AAR gives the airborne holding time. The results are displayed on the air traffic forecast windows of the workstations, as shown in Fig. 6. In this figure, the AAR is indicated as dots. The number of aircraft estimated to arrive is indicated as bars.

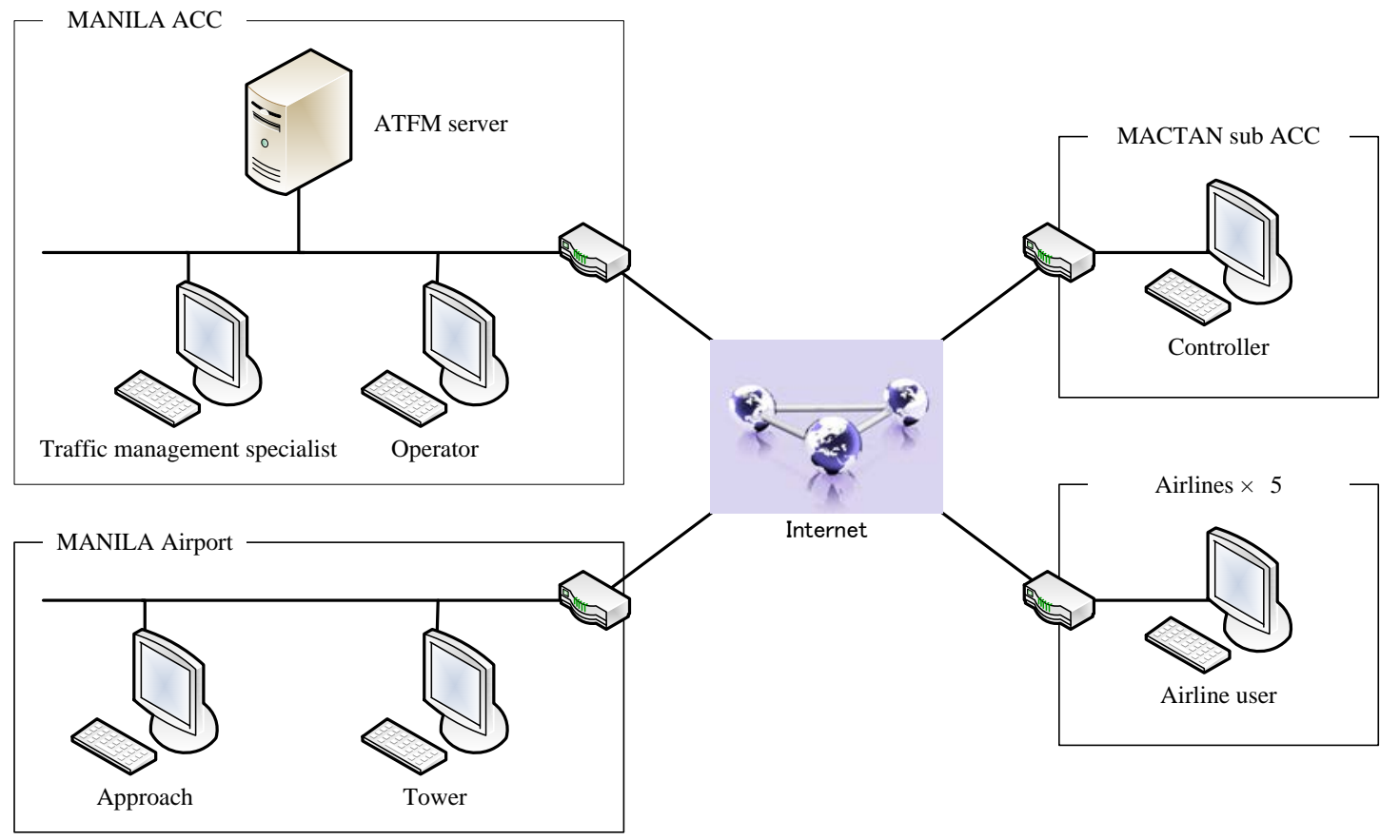

Fig. 5. System Configuration. 


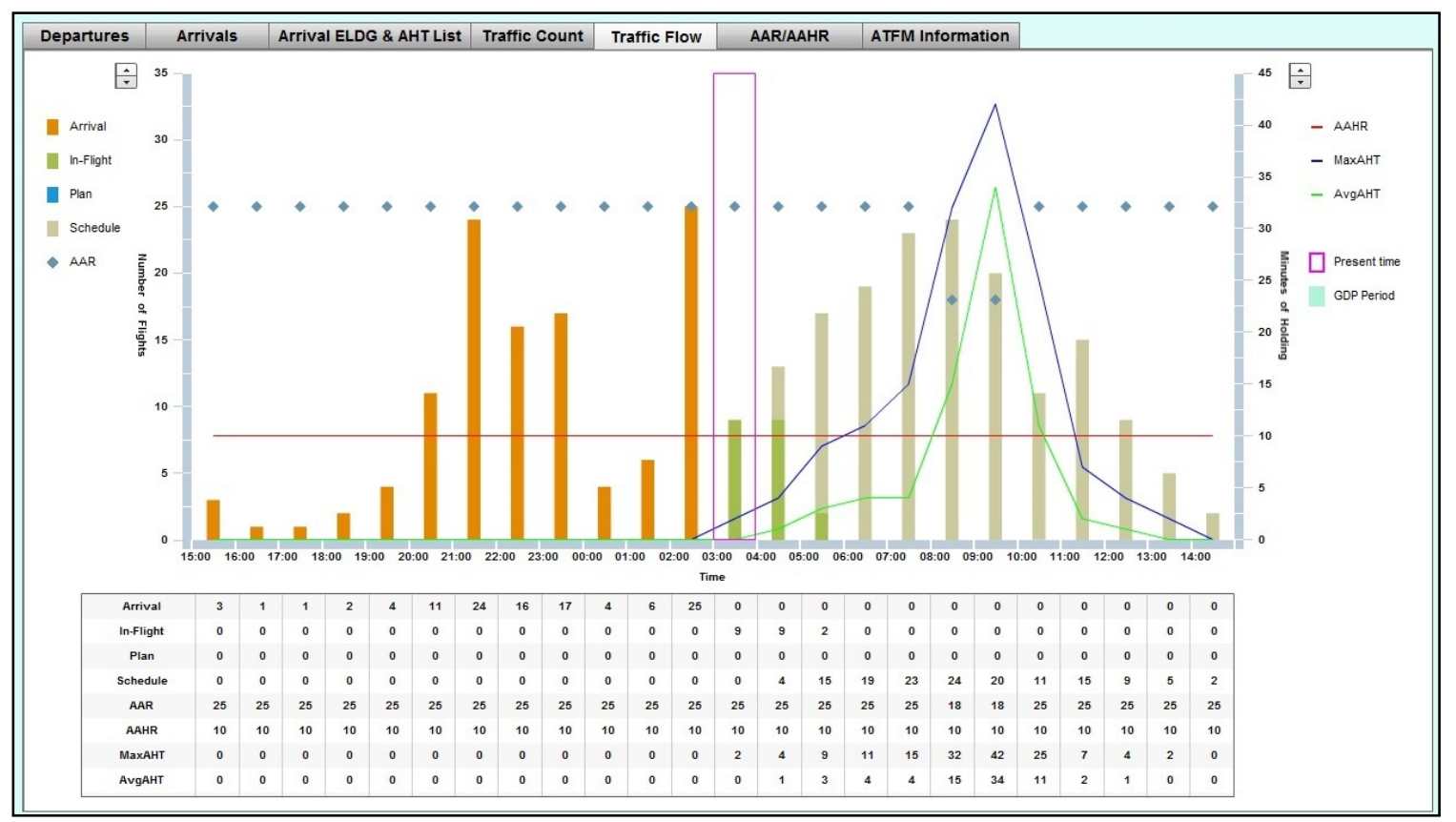

Fig. 6. Air traffic forecast window.

The number of aircraft is scaled using the $\mathrm{Y}$ axis on the left. The estimated holding time is indicated as curves and scaled using the $\mathrm{Y}$ axis on the right. The upper curve indicates the maximum and the lower one shows the average.

The number of aircraft estimated to arrive is based on OAG as mentioned before.
When a flight is canceled or delayed, its flight schedule is modified at a workstation by an operator at Manila ACC using the departures tab shown in Fig. 7. The holding time is then recalculated automatically on the server. The departures tab is also used when the aircraft departs.

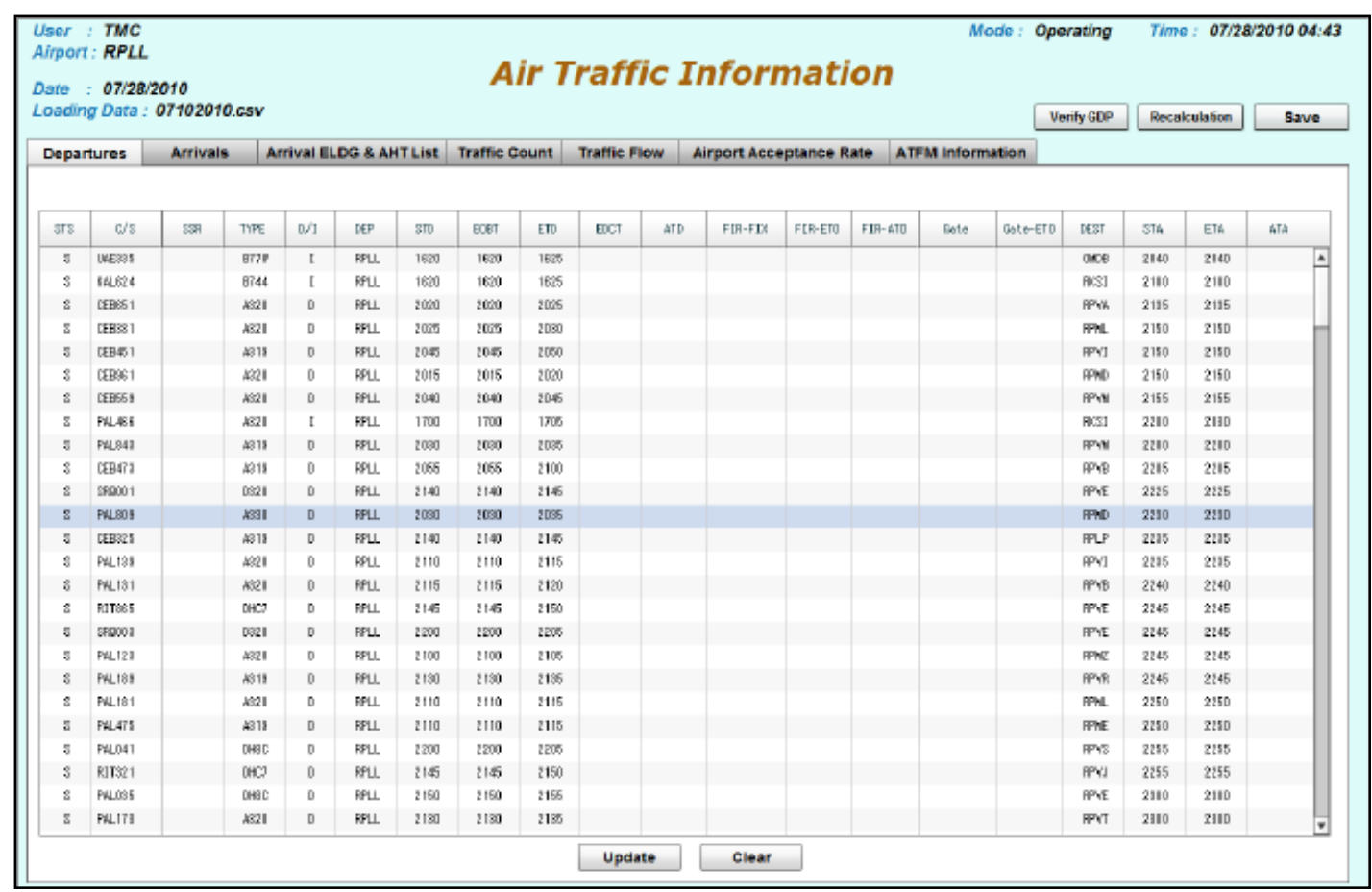

Fig. 7. Departures tab. 
M. ISHIDA: Operational Evaluation of Air Traffic Flow Management in the Philippines

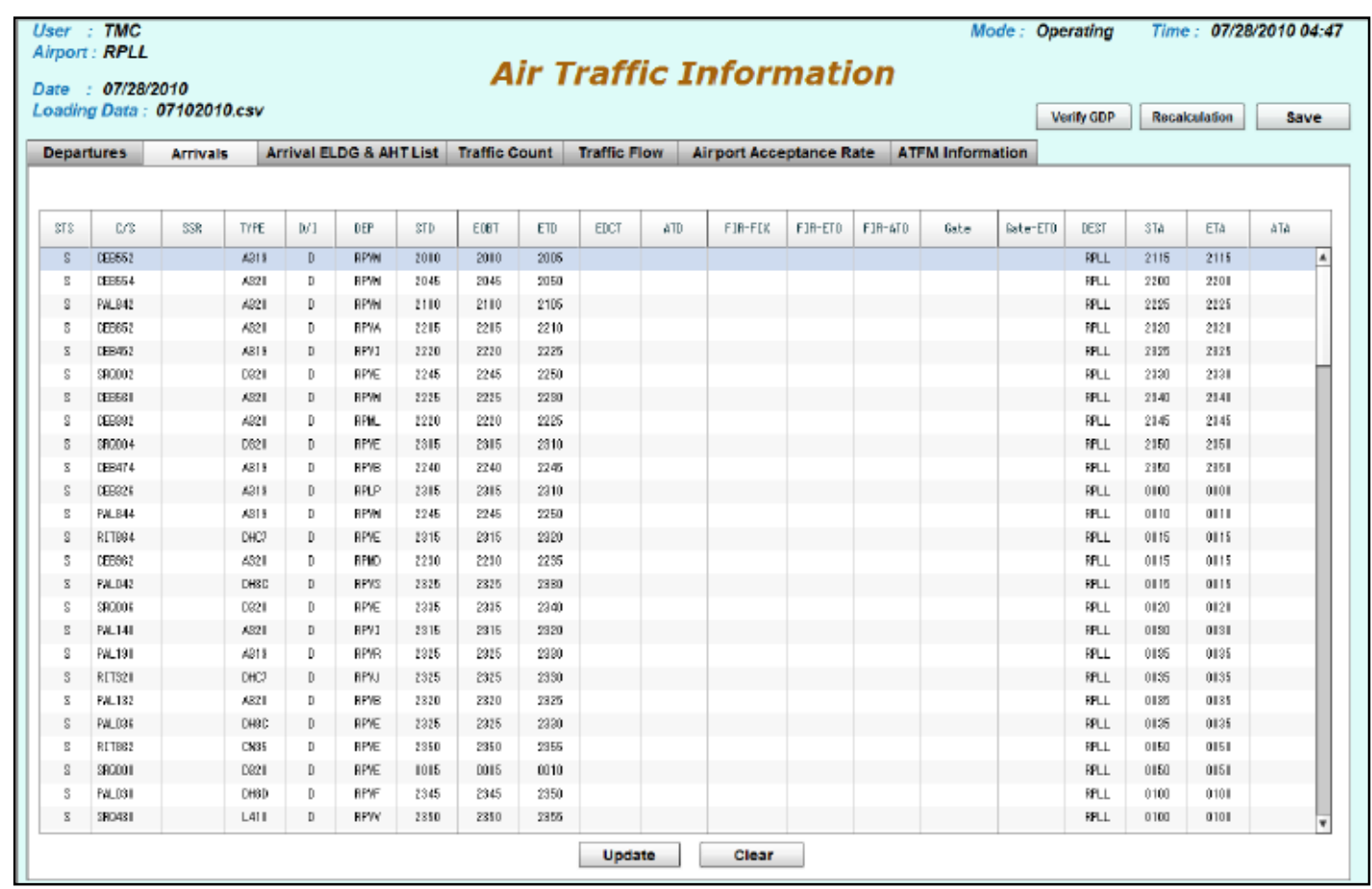

Fig. 8. Arrivals tab.

When an aircraft lands at NAIA, an operator at NAIA enters the actual time of arrival into the system via the workstation arrivals tab shown in Fig. 8. The holding times are then recalculated automatically. The arrivals tab is mainly for NAIA.

The flight schedule is modified manually using a keyboard or mouse. Generally, an interface for flight schedule information exchange with an existing system is indispensable for ATFM.
However, this ATFM system does not have an interface with the existing system yet. Since information exchange can be done by operators at NAIA manually as an alternative way, initial full operation did not require it.

When the flight schedule is modified due to a delay, departure or arrival, the air traffic volume is recalculated immediately. During congested periods, the estimated holding time exceeds the acceptable arrival holding rate (AAHR). The AAHR is indicated by the horizontal line in Fig. 9.

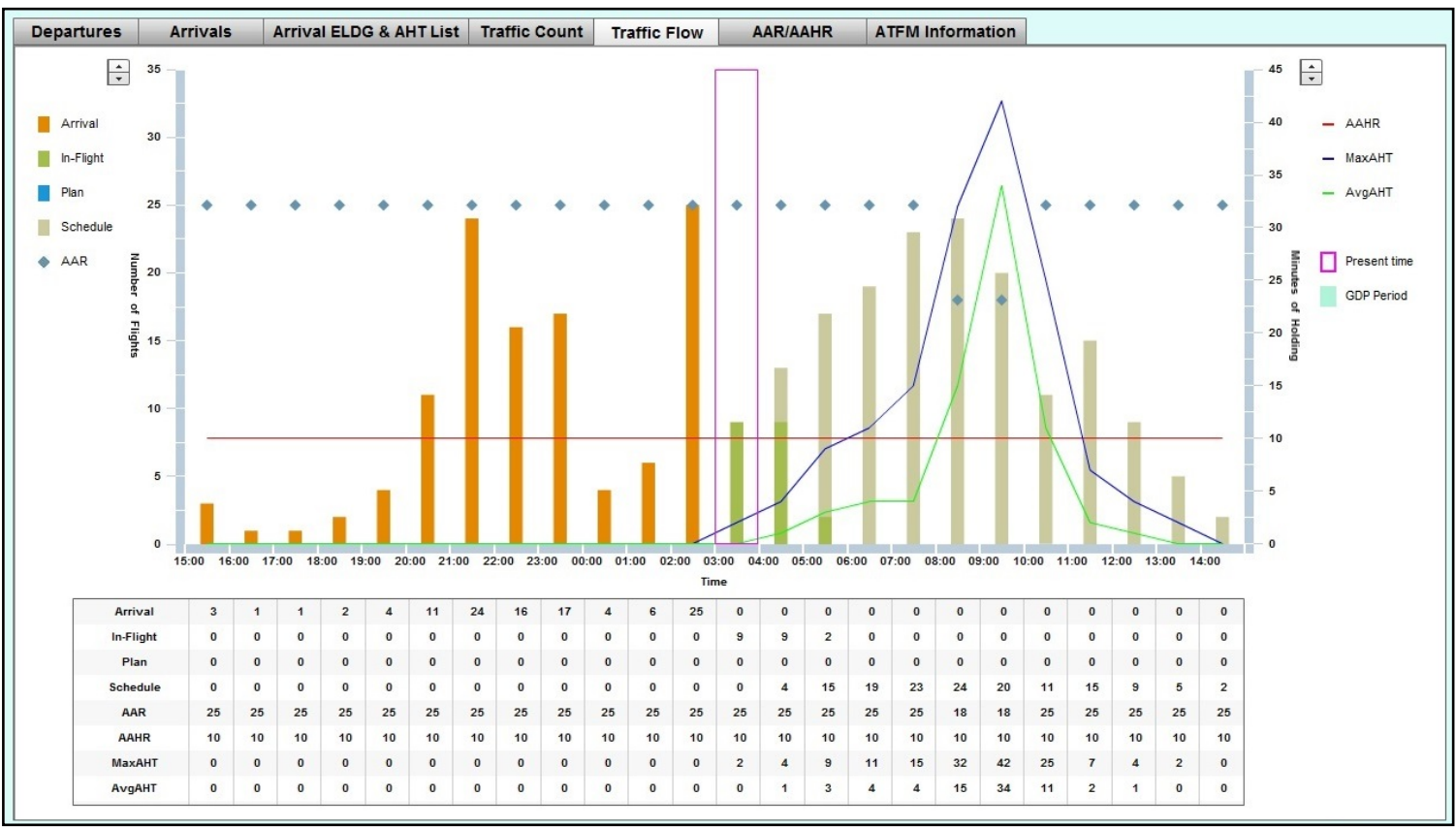

Fig. 9. Air traffic forecast before GDP. 


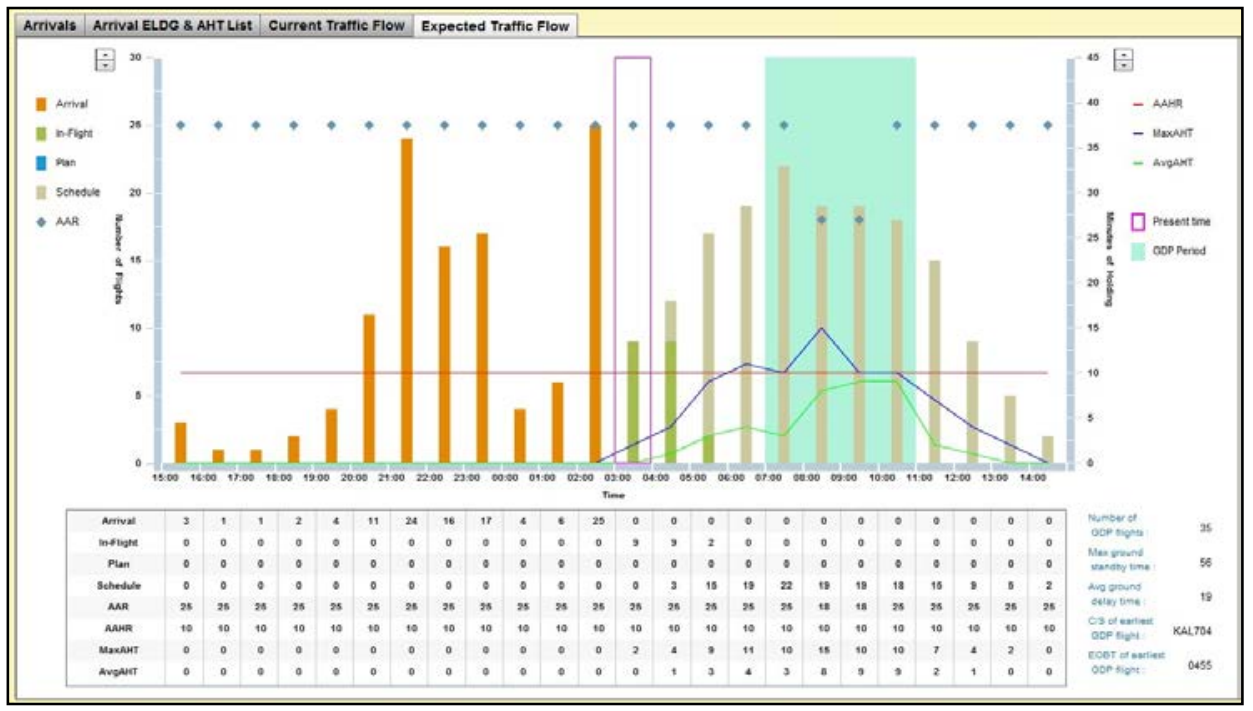

Fig. 10. Air traffic forecast under GDP.

\subsection{GDP operation}

Traffic management specialists at the Manila ACC continuously monitor the traffic volume. When they notice that the estimated holding time exceeds the AAHR, they start to use the GDP as necessary.

Traffic management specialists evaluate the impact of the GDP on NAIA using several parameters, such as a revised AAR and AAHR. The system has several measures for evaluating the GDP, as follows.

- Time to start GDP

- Duration of GDP

- Expected maximum holding time before GDP

- Expected average holding time before GDP

- Number of aircraft to be impacted by GDP

\section{- Expected maximum holding time under GDP \\ - Expected average holding time under GDP}

They also compare the traffic volume before the GDP and under it. In Fig. 9, the initial estimated holding time indicated by the curves exceeds the AAHR indicated by the straight line. However, Fig. 10 shows that the holding time is sufficiently mitigated under the GDP.

In addition, information on the aircraft that will depart first for NAIA during the GDP is evaluated. This information is useful for the air traffic controllers at the departure airport, since this information indicates the operational start time of GDP at the airport.

\begin{tabular}{|c|c|c|c|c|c|c|c|c|c|c|}
\hline \multirow{3}{*}{\multicolumn{2}{|c|}{ 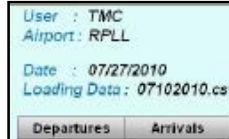 }} & \multirow{2}{*}{\multicolumn{6}{|c|}{ Air Traffic Information }} & \multirow{2}{*}{$\begin{array}{l}\text { Operating } \\
\text { Vere, Gro }\end{array}$} & \multicolumn{2}{|c|}{ Time: $07 / 27 / 201005: 26$} \\
\hline & & & & & & & & & Rocalciliatition & Save \\
\hline & & Arrival ELDQ \& AHT List & Traffic count & Trattic Flow & \multicolumn{3}{|c|}{ Airport Asceptance Rate ATFM Inforaation } & & & \\
\hline st8 & $c / 5$ & te & tesst & हाD & ECT & telid & Еत & anc & & int \\
\hline s & Patlies & Pilv & FuL & 17iI & & 1 & 1356 & & & 4 \\
\hline \& & Palciva & Pal & FUL & 1725 & & ' & 1910 & & & 0 \\
\hline s & PaLLOB & 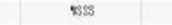 & Fu. & 1621 & & ' & 2010 & & & 0 \\
\hline s & cepeosis & $\cos s$ & FuL & 1665 & & ' & 2015 & & & 0 \\
\hline 8 & cesess 2 & peiv & FuL & 2015 & & ' & 2115 & & & 0 \\
\hline s & 口xteen 2 & शres & FLL & mi & & ' & 2120 & & & o \\
\hline$s$ & 때ew & Fiv & FLL & 2011 & & ' & 2210 & & & 0 \\
\hline$s$ & areacea & $=m$ & FL & $18 \mathrm{~s}$ & & ' & 2910 & & & o \\
\hline$s$ & PALEQ & PFI & FL & z11 & & ' & 396 & & & 0 \\
\hline$s$ & PAL5\% & 9III & FL & 1735 & & 1 & 2245 & & & 0 \\
\hline$s$ & IRESE & PeVA & FLL & 211 & & I & ssto & & & - \\
\hline$s$ & ap862 & Fri & FLL & $2 n$ & & ' & sas & & & - \\
\hline 8 & sancere & PPYE & FuL & 251 & & I & 2310 & & & 0 \\
\hline$s$ & o[Esen] & PRIV & mL & z" & & 1 & sat) & & & 0 \\
\hline$s$ & ceeterse & $\mathrm{PFH}$ & FPL & 225 & & I & 2365 & & & 0 \\
\hline$s$ & cresaric & PPVB & FOL & 2215 & & ' & 250 & & & 0 \\
\hline 8 & эorces & PPIE & PAL & ฆ11 & & I & 2550 & & & 0 \\
\hline$s$ & ㄸatrese & FLP & FL & 2011 & & 1 & 0010 & & & 0 \\
\hline$s$ & PALLA4 & Fiv & FL & za & & I & סוס & & & e \\
\hline 8 & [FEBSE & pero & ஈL & zais & & I & ळ16 & & & e \\
\hline 8 & Patore & Fis & FLL & 2311 & & I & 0015 & & & 0 \\
\hline 8 & 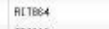 & PPVE & FOL & 2sa & & ' & $\infty 15$ & & & - \\
\hline$s$ & 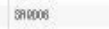 & PPIE & FUL & $\approx 4$ & & I & cose & & & 0 \\
\hline$s$ & PaL(19) & PPYI & FFL & कa & & 1 & 0010 & & & 0 \\
\hline 8 & PaL190 & pir & PU. & ซึ" & & I & 015 & & & 0 \\
\hline
\end{tabular}

Fig. 11. Estimated landing (ELDG) tab. 
When traffic management specialists decide to implement the GDP, they click the execute button on the GDP window. Then, the stakeholders (such as the traffic management specialists, air traffic controllers, and airline operators) are informed of GDP implementation via the Internet.

Another notable feature of the ATFM system is the shaded rectangle shown in Fig. 10. It is for the duration of the GDP and is shared with the stakeholders.

Moreover, the stakeholders can check the ground delay time, airborne holding time around NAIA, and estimated time of landing for each aircraft by clicking the estimated landing (ELDG) tab to get the results shown in Fig. 11. The estimated landing time is calculated based on the ground delay time and airborne holding time.

\section{Implementation Plan}

The Filipino air traffic controllers and airline operators did not have ATFM experience. Therefore, the ATFM was introduced step by step, as shown in Fig. 12. First, an ATFM server and workstations were installed at the ATFM unit and NAIA in the middle of October 2010.

\subsection{Training}

Initial operational training was held between October 19 and 21. Five people from the ATFM Working Group of the CAAP attended so as to prepare to oversee ATFM operations in the Philippines later. In addition, 15 people from NAIA, the Mactan sub-ACC, and other facilities participated. A photo of operational training is shown in Fig. 13.

After the initial operational training, four weeks of preparation for trial operation was scheduled. ATFM workstations were installed at the Mactan sub-ACC, which is near Cebu International Airport. The people from the ATFM Working Group were the main ones who then conducted an

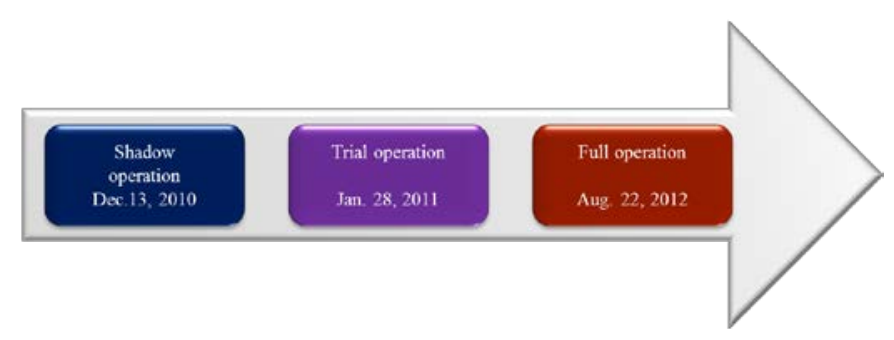

Fig. 12. Each step leading up to full operation.

ATFM seminar and operational training for the controllers at the Mactan sub-ACC. In the seminar, they reported on their training at Japan's ATMC, the philosophy behind air traffic flow management, and the ATFM system configuration. The Working Group also conducted the operational training. After that, they trained over 100 other controllers to deepen their understanding of ATFM features and operation.

\subsection{Shadow operation}

In December, ATFM shadow operation began. The purpose was to improve the ATFM operational skills inside

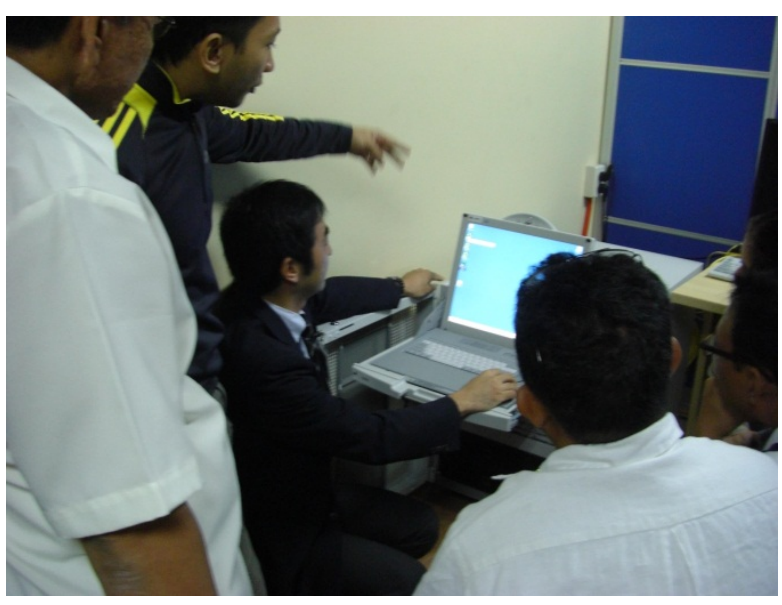

Fig. 13. Operational training.

the CAAP, not externally. Therefore, when the GDP was implemented, the EDCT was calculated along with the traffic scenario, but the EDCT was not issued to any airline operators.

The ATFM system consists of a server at the ATFM unit and five workstations. The workstations are installed at the Manila ACC, Mactan sub-ACC and Manila Tower. They are used to modify the flight schedules when there are flight delays, cancellations, departures or arrivals. However, to estimate the traffic volume accurately, it became necessary to improve the shadow operation data accuracy for the over 1,000 flights per day in the Philippines.

The shadow operation was conducted for over a month. However, it was not possible to make the data accuracy reach the desired level. To solve this problem, the CAAP hired about 10 specialists in charge of flight data modifications. After that, the accuracy of the estimated traffic volume improved and then reached the desired level for the next step: trial operation.

\subsection{Trial operation}

On January 28, 2011, trial operation started. Initially, it was only used to mitigate traffic congestion during the two busiest hours, and many issues to solve became apparent. Airline operators were involved in the trial operation. Therefore, cooperation with the airline operators was very important. The Working Group did its best to improve communications with the airline operators so the trial operation would go well. In particular, receiving information on flight delays from the airline operators and issuing EDCTs to them were very important.

The Working Group held ATFM meetings with the airline operators periodically. In addition, they set up points-of-contact to explain the reasons for ground delays.

In September 2011, the CAAP evaluated the trial operation and reported that the holding time decreased from 2,891 to 1,905 minutes for the same period in 2010. They therefore achieved a reduction of 34\% compared with that in 2010 . 


\subsection{Full operation}

In 2012, full operation started with improved accuracy of air traffic volume forecasts and expanded GDP operations according to ATS orders, ${ }^{2)}$ as described below.

1) The airline operators provide daily estimated off-block time (EOBT) updates and flight cancellation information before $8 \mathrm{AM}$ by fax or email.

2) Traffic management specialists check for constraints and change the AAR as necessary.

3) The flights subject to the GDP are all :

- domestic airlines' flights,

- general aviation flights, and

- other civilian flights flying $\mathrm{VFR}^{+}$to IFR.

\subsection{Expansion plans}

The CAAP plans to provide flow control for flights operating at Tagbilaran Airport and to assist Kalibo Airport with flow control.

\section{Conclusion}

In 2012, the CAAP presented its second evaluation of GDP operations. The report stated there are seven reasons for airborne holding: 1) weather, 2) terminal congestion, 3) runway changes, 4) special operations, 5) incidents such as emergencies, 6) equipment failures and 7) others. Their ratios are shown in Fig. 14, with weather ranked first at 30\%. In contrast, in 2010, almost all of the airborne holding was caused by heavy traffic. Proactive analysis of the reasons for airborne holding is important for improving operations and making them more efficient. This is because it gives traffic management specialists more options for dealing with heavy traffic in advance.

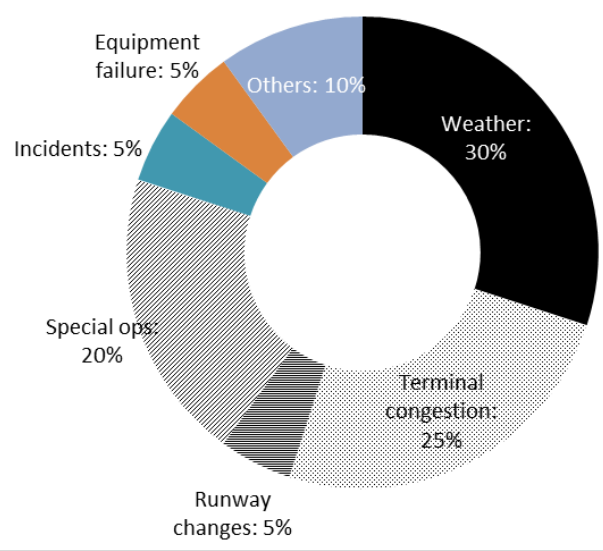

Fig. 14. The reasons for holding (2012).

As a result of the NAIA progress as of 2012, the holding time decreased to 1,030 minutes in the same period described above. Therefore, a reduction of $64.4 \%$ was achieved, as shown in Fig. 15.

\section{Acknowledgments}

The support of the Civil Aviation Authority of the Philippines, Japan International Cooperation Agency, Japan Civil Aviation Bureau, and Electronic Navigation Research Institute is gratefully acknowledged.

\section{References}

1) Japan External Trade Organization (JETRO) http://www.jetro.go.jp/world/asia/ph/stat_01/

2) CAAP, ATS ORDER No. 01-12, August 22, 2012

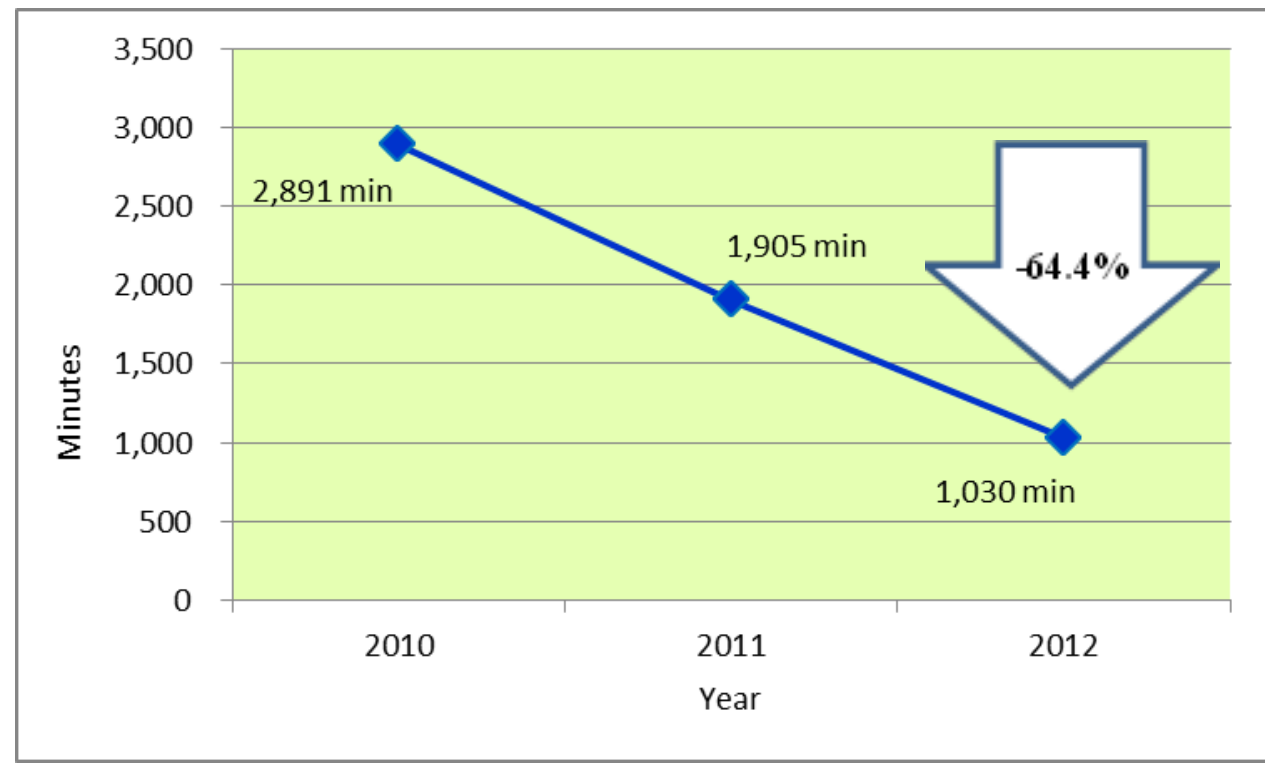

Fig. 15. Duration of airborne holding time.

\footnotetext{
${ }^{+}$Visual Flight Rules
} 